\title{
Malaria en gestante con diagnóstico tardío de infección por el virus de la inmunodeficiencia humana, en una comunidad indígena de la Amazonía peruana
}

\author{
Stalin Vílchez-Rivera ${ }^{1,2, a}$, Claudia Liliana Asiú-Fernández ${ }^{2, b}$, Amina Andrea Daoudi-Tume ${ }^{2, b}$, \\ Dante Oriel Díaz-Agurto 2,b, Rubens Amado Llontop-Clavo 2,b , Juan José Max Perales-Díaz 2,b, \\ Jhonatan Josue Ynfante-Patiño ${ }^{2, b}$
}

\section{RESUMEN}

Se describe un caso de malaria en una gestante con diagnóstico tardío de infección por el virus de la inmunodeficiencia humana $(\mathrm{VIH})$, en una comunidad indígena de la Amazonía peruana. El tratamiento implementado después del diagnóstico fue suficiente para la madre, sin embargo el recién nacido por cesárea fallece a los 10 días. La paciente tuvo desconocimiento acerca de la infección por el VIH. Este caso de coinfección de malaria y VIH en una gestante indígena de la Amazonía evidencia el desconocimiento sobre el VIH y del control durante el embarazo en esta población, pudiendo terminar en mortalidad neonatal.

Palabras clave: VIH, Malaria, Plasmodium vivax, gestación, mortalidad neonatal (Fuente: DeCS-BIREME).

\section{Malaria in pregnant women with late diagnosis of human immunode- ficiency virus infection, in an indigenous community in the Peruvian Amazon}

\begin{abstract}
A case of malaria is described in a pregnant woman with a late diagnosis of human immunodeficiency virus (HIV) infection, in an indigenous community in the Peruvian Amazon. The treatment implemented after diagnosis was sufficient for the mother, however the newborn by caesarean section dies at 10 days. The patient was unaware of HIV infection. This case of malaria and HIV coinfection in an indigenous pregnant woman in the Amazon shows the lack of knowledge about HIV and the control during pregnancy in this population, which may end in neonatal mortality.
\end{abstract}

Keywords: HIV, malaria, Plasmodium vivax, gestation, neonatal mortality (Source: MeSH-NLM)

\footnotetext{
${ }_{1}^{1}$ Servicio de medicina interna, Hospital Regional Lambayeque, Chiclayo, Perú.

2 Facultad Medicina Humana, Universidad Particular de Chiclayo, Chiclayo, Perú.

a Médico internista.

${ }^{\mathrm{b}}$ Estudiante de medicina.
} 


\section{INTRODUCCIÓN}

La infección por el virus de la inmunodeficiencia humana $(\mathrm{VIH})$, perjudica la inmunidad y podría aumentar la susceptibilidad del hospedero a la malaria. La malaria en mujeres embarazadas e infectadas por el VIH tiene consecuencias negativas significativas para la salud materna y el resultado del embarazo (1). La infección placentaria por el parásito de la malaria, así como la infección materna por VIH aumenta la mortalidad neonatal; por lo tanto la quimioprofilaxis de la malaria durante el embarazo reduce la probabilidad de transmisión vertical del $\mathrm{VIH}$, además de reduce la carga de la infección de la malaria durante el embarazo, el bajo peso al nacer asociado con la malaria y su posterior efecto en la supervivencia (2).

La infección por el VIH durante los años entre 1990 al 2015 en la región Amazonas presentó un total de 684 casos (277 mujeres y 407 hombres), de los cuales, 39,5\% fueron reportados por la Red de Salud Condorcanqui y $23 \%$ por la Microrred Imaza, territorios que concentran a las comunidades indígenas. Cabe señalar, que el $70 \%$ (479) de los casos de $\mathrm{VIH}$ fueron notificados en el periodo 2012-2015 probablemente por el mayor acceso a la prueba de $\mathrm{VIH}$ (3). Por otro lado, desde el 2015 los casos de malaria han aumentado en $71 \%$, y el $95 \%$ del total se concentra en áreas donde se han debilitado los esfuerzos contra la enfermedad, donde mucho de los afectados son poblaciones indígenas (4).

La malaria y el VIH son problemas de salud mundial en los países en desarrollo; causan más de cuatro millones de muertes al año. Estas dos infecciones interactúan bidireccional y sinérgicamente entre sí. La infección por VIH aumenta el riesgo en la infección por malaria, que a su vez facilita la tasa de transmisión. La infección por malaria también se asocia con una fuerte activación de las células CD4 + y la sobre-regulación de citoquinas pro inflamatorias proporcionando un microambiente ideal para la propagación del virus entre las células $\mathrm{CD} 4$ + y para la replicación rápida del VIH1. Además, la malaria aumenta la carga viral en la sangre por diferentes mecanismos. Altas concentraciones de ARN viral en sangre son predictivos de la progresión de la enfermedad, y se correlacionan con el riesgo de transmisión sanguínea vertical y sexual del virus $(5,6)$.

Una revisión de la problemática de gestantes indígenas viviendo con el $\mathrm{VIH}$, evidencia la poca información acerca de prácticas de cuidado y prevención, así como la necesidad de un enfoque médico para atender a las gestantes y mujeres con VIH (7)."Las pasajeras, pero recurrentes subidas de las cargas virales en personas que viven con SIDA que están relacionadas con repetidos accesos de malaria aumentan la prevalencia del VIH y alimentan la expansión de ambas enfermedades a escala poblacional. Sin embargo, un control pronto y eficaz de la malaria, junto con la abstinencia y el uso de condón, pueden reducir de forma eficaz el aumento y expansión del VIH" (8).

El objetivo del reporte es describir un caso clínico de coinfección entre malaria y $\mathrm{VIH}$ en una gestante indígena de la Amazonía peruana; asimismo, difundir la necesidad de políticas de prevención y educación sobre la coinfección en comunidades nativas y la importancia de los controles y el tratamiento oportuno para evitar muertes maternas como neonatales.

\section{REPORTE DE CASO}

Gestante de 17 años ingresa al servicio de emergencia del Hospital Regional Lambayeque (20/11/2018), procedente de la comunidad nativa de Bichanak, en el distrito de Imaza, provincia de Bagua, departamento de Amazonas, Perú; zona selva a $349 \mathrm{~m}$ s. $\mathrm{n}$. m. de altitud y con una población de 1507 personas.

Tres meses antes, a los cinco meses de embarazo, acude por presentar sensación de alza térmica (no cuantificada), asociado a cefalea localizada en región frontoparietal de tipo punzante, intermitente, en escala visual análoga (EVA) 6/10 que calma en decúbito dorsal y agrava en posición sedente; además, la paciente refiere presentar tos seca intermitente y que se exacerbaba en las noches; presenta deposiciones líquidas, color amarillo con presencia de moco y con frecuencia de cinco a seis veces por día. En la región bucal presentó lesiones aterciopeladas blanquecinas asociadas a odinofagia.

Dos meses antes del ingreso, a los seis meses de embarazo, tuvo sintomatología persiste y se agrava, la tos se vuelve persistente y productiva con expectoración blanquecina. La fiebre se acompaña de diaforesis diurna y nocturna (cuatro cambios de polo al día). La cefalea aumenta en intensidad (EVA: 8/10) y se asocia a náuseas y vómitos. Por lo que acude a posta de su comunidad donde le recetan dos medicamentos (ibuprofeno y no refiere el segundo) calmándole la cefalea, fiebre y diarrea.

Un mes antes del ingreso, a los siete meses de embarazo, desaparecen las lesiones aterciopeladas blanquecinas en la boca (presuntamente candidiasis oral), las deposiciones se tornan más sólidas, color marrón y olor sui generis y con frecuencia de tres veces al día. La sintomatología persiste, a la fiebre se le agrega escalofríos y la tos productiva tiene periodos de expectoración amarillenta con blanquecina.

A los ocho meses (el mes del ingreso), ya no presenta tos productiva, aparecen contracciones uterinas por lo que es llevada al hospital de Bagua donde le realizan una prueba rápida de $\mathrm{VIH}$ resultando positiva, y es referida al Hospital 
Regional Lambayeque, lugar donde se le realiza una cesárea satisfactoria (23/11/2018). Diez días después de la cesárea el neonato fallece $(3 / 12 / 2018)$.

En el examen físico encontramos fiebre $\left(38,6^{\circ} \mathrm{C}\right)$, con una frecuencia respiratoria de 26 respiraciones por minuto y una frecuencia cardiaca de 105 latidos por minuto. La piel se encuentra hipertérmica y no presenta edemas. Se observó onicomicosis en ambos miembros superiores, y denopatías en ganglios cervicales izquierdos, duros, móviles, de bordes irregulares y de aproximadamente un centímetro. Tiroides no palpable, ausencia de signos de hipotiroidismo. Tórax simétrico, sin presencia de tiraje, vibraciones vocales y sonoridad conservada, no presenta de estertores, sibilante ni roncantes. No presenta ingurgitación yugular, pulso alternante, desplazamiento de choque de punta a la maniobra de Harvey, soplos en focos pulmonar ni tricuspídeo a la maniobra de Rivero Carvalho. Tampoco presenta soplos en focos aórtico ni mitral a la maniobra de Valsalvă. El abdomen se encontró dentro de características normales y estigmas hepáticos ausentes. Neurológicamente la paciente estuvo despierta, con Escala de Glasgow: 15/15, sin disartria, signo de Babinski ausente, y sin déficit motor. Tampoco presentó signos meníngeos. Variación ponderal de $23 \mathrm{~kg}$ en 10 meses (marzo a diciembre del 2018).

Durante hospitalización se le realiza prueba de $\mathrm{VIH}$ donde se confirma el diagnostico, además al realizarle el examen de gota gruesa da un resultado positivo observándose trofozoitos medianos de Plasmodium vivax. Ingresa con un recuento de 1600 leucocitos/uL, con $50 \%$ de neutrófilos segmentados, hemoglobina de 6,6 g/dl, 2,39 millones de hematíes/ uL (bicitopenia: leucopenia y anemia) y 234000 plaquetas/ uL. Una glucemia basal de $85 \mathrm{mg} / \mathrm{dl}$ y urea de $18 \mathrm{mg} / \mathrm{dl}$. Las transaminasas TGO y TGP estuvieron con niveles de 103 $\mathrm{U} / \mathrm{L}$ y $30 \mathrm{U} / \mathrm{L}$, respectivamente.

Se inició tratamiento antirretroviral con tenofovir y emtricitabina; y antimicótico con fluconazol. También se trató la anemia con sulfato ferroso y vitamina B12, y antibioticoterapia con ceftazidima y clindamicina. La malaria se trató con cloroquina y primaquina. La paciente respondió lentamente al tratamiento y es dada de alta estable.

\section{DISCUSIÓN}

Globalmente, Plasmodium spp. causan cien a doscientos millones de casos de malaria o paludismo, y aproximadamente dos millones de muertes al año. El VIH/SIDA y la malaria tienen grandes áreas de endemicidad compartida. La malaria no actúa como una infección oportunista, y no acelera la progresión a SIDA. Sin embargo, estudios in vitro han descrito un aumento de replicación viral cuando este se expone a antígenos del Plasmodium (mediado por TNF alfa) (9). Clínicamente el paludismo disminuye de forma transitoria el número de linfocitos CD4+ (tanto en sujetos infectados por el VIH como en los no infectados). Además, la carga viral del
VIH aumenta cuando se produce una infección por Plasmodium spp., más o menos en $0,25 \log (10)$.

En la influencia de la infección por el VIH sobre la malaria pueden distinguirse tres situaciones: a) Cuando la coinfección se produce de forma simultánea, se estima que la respuesta frente a Plasmodium no va a estar afectada; b) En personas con semiinmunidad adquirida y coinfectados con posterioridad por el VIH, se podría producir una disminución de la respuesta inmune frente al Plasmodium debido a la disminución de linfocitos CD4+ o por un defecto cualitativo de la respuesta inmune; y c) En individuos infectados por el $\mathrm{VIH}$ sin contacto previo con malaria, el grado de inmunodepresión condicionaría la respuesta.

En las series de casos clínicos publicadas de paludismo importado en pacientes $\mathrm{VIH}{ }^{(11,12)}$, se reportó que el recuento de linfocitos CD4+ inferior a 350 por microlitro se asociaron a mayor gravedad. "Sin embargo estudios han demostrado que si aumenta el riesgo fetal durante el embarazo de mujeres co-infectadas. Los efectos beneficiosos de la paridad son atenuados en las mujeres coinfectadas (estudios en Malawi). Existe también un efecto sinérgico sobre la mortalidad neonatal. Las mujeres multíparas infectadas con $\mathrm{VIH}$ deben tener prevención de la malaria, es decir tratamiento mensual con Pirimetamina/ Sulfadoxina, que ha sido efectivo y seguro"(13). A esto se adiciona la limitación que todos los pacientes provenían de zonas con transmisión estable de malaria (con las implicaciones que ello tiene sobre la semiinmunidad) (14).

No obstante, la ausencia de tratamiento antirretroviral es un rasgo que caracteriza a este grupo de pacientes, con paludismo importado e infección por $\mathrm{VIH}$, formado fundamentalmente por nativos que frecuentemente desconocen que están infectados por el VIH, y en los que se realiza el diagnóstico durante el episodio de paludismo; o que aun conociendo que están infectados por $\mathrm{VIH}$ no han tenido acceso a tratamiento antirretroviral en su lugar de origen.

Conflicto de intereses: Los autores declaran no tener conflicto de intereses.

Financiamiento: Autofinanciado

REFERENCIAS BIBLIOGRAFICAS

1. Allen S1, Van de perre $P$, Serufilira A, Lepage $P$, Carael M, DeClercq A, Tice J, Black D, Nsengumuremyi F, Ziegler J, et al. Human immunodeficiency virus and malaria in a representative sample of childbearing women in Kigali, Rwanda. J Infect Dis. 1991; 164(1): 67-71.

2. Bloland PB, Wirima J, Steketee TW, Chilima B, Hightower A, Breman JG (1995) Maternal HIV infection and infant mortality in Malawi: evidence for increased mortality due to placental malaria infection. AIDS. 1995; 9(7): 721-6.

3. Huamán B, Gushiken A, Benites C, Quiroz F, García-Fernández L. Prevención de la transmisión materno-infantil del VIH en gestantes y madres awajún y wampis de la región Amazonas en Perú. Rev Peru Med Exp Salud Pública. 2017; 34(4):627-32.

4. Organización Panamericana de la Salud. Malaria [en línea]. Perú. 2018. 
[Fecha de acceso 5 de diciembre de 2018]. Disponible en: https://www. paho.org/per/index.php?option=com_joomlabook\&view=topic\&id=33

5. Alemu A, Shiferaw Y, Addis Z, Mathewos B, Birhan W. Effect of malaria on HIVIAIDS transmission and progression. Parasites and Vectors. 2013; 6:18.

6. Torres Fajardo, KJ. Evaluación de la respuesta inmune en malaria sintomática y asintomática por Plasmodium falciparum en la Amazonia Peruana [en línea]. Perú: Universidad Peruana Cayetano Heredia; 2015. Disponible en: http://repositorio.upch.edu.pe/bitstream/handle/upch/757/Evaluacion_TorresFajardo_Katherine.pdf?sequence=1\&isAllowed=y

7. Portocarrero J. VIH en gestantes indígenas: un reto para la salud pública peruana. Rev Peru Med Exp Salud Pública. 2015; 32(3):546-54.

8. Grupo de trabajo sobre tratamientos del VIH (gTt-VIH). Las epidemias del VIH y la malaria se impulsan mutuamente y tienen que ser abordadas conjuntamente [en línea]. España: GTT-VIH; 2006. [Fecha de acceso 5 de diciembre de 2018]. Disponible en: http://gtt-vih.org/actualizate/actualizacion en tratamientos/12-12-06?fbclid=IwAR2Dy z1 LpljJbVQylc622gVLP. qi8WRh1 1 H7H-zu6lmIQ8YX5b0yGeg6eU0w

9. Herrero MD, Rivas P, Rallón NI, Ramírez-Olivencia G, Puente S. HIV and malaria. AIDS Rev. 2007; 9(2):88-98.

10.Idemyor V. Human immunodeficiency virus (HIV) and malaria interaction in sub-Saharan Africa: the collision of two Titans. HIV Clin Trials. 2007; $8(4): 246-53$.

11.Van Geertruyden JP, Mulenga M, Mwananyanda L, Chalwe V, Moerman F, Chilengi R, et al. HIV-1 immune suppression and antimalarial treatment outcome in Zambian adults with uncomplicated malaria. J Infect Dis. 2006; 194(7): 917-25

12.Shah SN, Smith EE, Obonyo CO, Kain KC, Bloland PB, Slutsker L, et al. HIV immunosuppression and antimalarial efficacy: sulfadoxine-pyrimethamine for the treatment of uncomplicated malaria in HIV-infected adults in Siaya, Kenya. J Infect Dis. 2006; 194(11):1519-28.

13.Alvarado FS.VIH/SIDA en el Trópico [en línea]. Colombia: Revista de Salud Pública; 2001. Disponible en: http://www.scielo.org.co/pdf/rsap/v3s1/01240064-rsap-3-s1-00131.pdf

14.Cuadros González J. Malaria importada en España. Rev Clín Española. 2012; 212(1):24-5.

Revisión de pares: Recibido: 01/09/2019 Aceptado: 28/12/2019 